\title{
GNA11 Mutation Analysis
}

National Cancer Institute

\section{Source}

National Cancer Institute. GNA11 Mutation Analysis. NCI Thesaurus. Code C157182.

A procedure used to detect and identify mutations in the GNA11 gene. 